\section{Management of Congenital Diaphragmatic Hernia}

Dear Editor,

$\mathrm{T}$ his is with reference to the "Radiological Quiz" published in MJAFI 2005;61:50 \& 78. The authors mention that immediate action required in congenital diaphragmatic hernia, is inserting a feeding tube in stomach, stopping feeds and operating the patient as an emergency. A neonate with congenital diaphragmatic hernia usually presents with respiratory distress and may have anomalies of other organ systems. Respiratory distress in newborn is a contradiction to enteral feeds. In addition to inserting a feeding tube for decompression, it is essential that these babies are not resuscitated with bag and mask as this pushes air into intrathoracic stomach and viscera which further compresses the mediastinal structures. These babies should be intubated.

The treatment of congenital diaphragmatic hernia does not involve closure of diaphragm after reducing the viscera, as the physical compression is not the sole abnormality. The postnatal mass effect of the herniated viscera is a minor factor in the cardio respiratory compromise compared with the pulmonary hypertension and hypoplasia [1].

Congenital diaphragmatic hernia was once considered a surgical emergency. Recognition of the role of pulmonary hypertension in

\section{Reply}

The aim of Radiology Quiz is to highlight the importance of early investigation and diagnosis of congenital diaphragmatic hernia $(\mathrm{CDH})$ in a neonate.

If diagnosis is made antenatally, then no feeds are given. The neonate in the quiz was diagnosed when breathlessness developed after the first feed and radiographs taken.

As per Wiseman Classification of CDH, Type I (wherein herniation occurs during bronchial branching leading to severe bilateral pulmonary hypoplasia) is uniformly fatal. In Type II (herniation during distal bronchial branching leading to unilateral pulmonary hypoplasia) survival is possible and these are usually picked up in antenatal scans. Type III (herniation in late pregnancy with compression of otherwise normal lung) and Type IV (post natal herniation with compression of otherwise normal lung) show excellent prognosis.

The first priority of treatment for Bochdalek hernias is adequate ventilatory support. Energetic resuscitation includes new techniques such as high frequency oscillation and ECMO which are not available routinely. It is obvious that babies have to be stabilized before surgery for diaphragmatic repair. Early repair is important the decision being made on proper clinical evaluation addition to pulmonary hypoplasia and the adverse effects of operative repair on pulmonary function has caused a shift in management approach. Opinion regarding the timing of surgical repair has gradually shifted from emergent repair to a policy of stabilization using a variety of ventilatory strategies prior to operation [2]. If the infant stabilizes and demonstrates stable pulmonary vascular resistance without significant right to left shunt, repair of the diaphragm is performed at 24-72 hours of age. If stabilization is not possible, most infants will require extra corporeal membrane oxygenation support (ECMO) initially in addition to surgical repair and ventilatory support.

\section{References}

1. Hartman GE. Diaphragmatic Hernia. In: Behrman RE, Kliegman RM, Jenson HB, editors. Nelson textbook of Paediatrics. $7^{\text {th }}$ ed. Philadelphia: Elsevier, 2004; 1353-55.

2. Clark RH, Hardin WD, Hirschl RB, Jaksic T, Lally KP, Langham MR, Wilson JM. Current surgical management of congenital diaphragmatic hernia - a report of the congenital diaphragmatic hernia study group. J Pediatr Surg 1998; 33: 1004-9.

Wg Cdr Daljit Singh*

${ }^{*}$ Classified Specialist (Paediatrics), CH (AF), Bangalore.

rather than by defining a time frame in hours.

Surgery has to be performed at the earliest as a definitive treatment for $\mathrm{CDH}$. The abdominal contents must be returned to the abdomen for decompression of the lungs. Associated visceral anomalous vascular supply to spleen or liver have to be evaluated during surgery. It has been found that 39 to $77 \%$ survive after repair.

The take home message of the quiz is $\mathrm{CDH}$ is a neonatal emergency where early diagnosis is made radiologically (on the basis of radiographs and ultrasonography) and management requires energetic resuscitation and stabilization for definitive surgical repair of the defect at the earliest.

\section{References}

1. Langer JC. Congenital Diaphragmatic Hernia Chest Clinics of $\mathrm{N}$ Am 8, 1998: 295-14.

2. Feldman M, Friedman S, Sleisenger HM. Abdominal Hernias and complications including gastric volvulus. In: Gastrointestinal and Liver Pathology, diagnosis and management. Saunders, $7^{\text {th }}$ Edn, 1997: 369-82.

Surg Cdr PG Handa*

"Classified Specialist (Radiology), INHS ASVINI, Mumbai. 